\title{
Tandem 13-Lipoxygenase Genes in a Cluster Confers Yellow-Green Leaf in Cucumber
}

\author{
Yin Ding ${ }^{1,2, \dagger}$, Wei Yang ${ }^{1, \dagger}$, Chenggang Su ${ }^{1}$, Huihui Ma ${ }^{1,2}$, Yu Pan ${ }^{1,2}$, Xingguo Zhang ${ }^{1,2}$ and \\ Jinhua $\mathrm{Li}^{1,2, *(1)}$ \\ 1 Key Laboratory of Horticulture Science for Southern Mountainous Regions, Ministry of Education, College \\ of Horticulture and Landscape Architecture, Southwest University, No.2 Tiansheng Road, Beibei, \\ Chongqing 400715, China; dd815988458@email.swu.edu.cn (Y.D.); shucaitomato@gmail.com (W.Y.); \\ suchenggang@swu.edu.cn (C.S.); h2394978356@email.swu.edu.cn (H.M.); pany1020@swu.edu.cn (Y.P.); \\ zhangdupian@swu.edu.cn (X.Z.) \\ 2 State Cultivation Base of Crop Stress Biology for Southern Mountainous land of Southwest University, \\ Academy of Agricultural Sciences, Southwest University, Beibei, Chongqing 400715, China \\ * Correspondence: ljh502@swu.edu.cn; Tel.: +86-23-68250974; Fax: +86-23-68251274 \\ $\dagger$ These authors contributed equally to this work.
}

Received: 17 May 2019; Accepted: 22 June 2019; Published: 25 June 2019

check for updates

\begin{abstract}
Some lipoxygenase (LOX) isoenzymes can co-oxidize carotenoids. Carotenoids are collectors of light energy for photosynthesis and can protect plants from reactive oxygen species and coloration. This study isolated the cucumber (Cucumis sativus L.) yellow-green leaf mutant (ygl1), which had yellow-green leaves with decreased chlorophyll synthesis, increased relative carotenoid content, and delayed chloroplast development. Genetic analysis demonstrated that the phenotype of ygl1 was caused by a recessive mutation in a nuclear gene. The bulked segregants were resequenced, and the candidate $y g l 1$ locus identified was mapped to the $9.2 \mathrm{~kb}$ region of the chromosome 4 . Sequence analysis revealed that ygl1 encodes the tandem 13-LOX genes in a cluster. Four missense mutations were found in four tandem 13-LOX genes (Csa4M286960, Csa4M287550, Csa4M288070, and Csa4M288080) in the ygl1 mutant, and the four 13-LOX genes showed high similarity with one another. The transient RNA interference and virus-induced gene silencing of these genes simultaneously resulted in yellow-green leaves with a reduced amount of chloroplasts and increased relative carotenoid content, which were observed in the ygl1 mutant. This evidence supported the non-synonymous SNPs (Single Nucleotide Polymorphism) in the four tandem 13-LOX genes as being the causative mutation for the yellow-green leaves. Furthermore, this study provides a new allele for breeding cucumbers with yellow-green leaves and serves as an additional resource for studying carotenoid biosynthesis.
\end{abstract}

Keywords: 13-lipoxygenase; gene cluster; yellow green leaf; cucumber; carotenoids

\section{Introduction}

Chlorophyll (Chl) content and chloroplast development are directly related to the efficiency of plant photosynthesis [1]. Elevated levels of carbon dioxide $\left(\mathrm{CO}_{2}\right)$ result from leaf photosynthesis and increase crop yield potential [2]. The chloroplasts of green plants can fix $\mathrm{CO}_{2}$ and transform them into organic substances via photosynthesis. In chloroplasts, $\mathrm{Chl}$ molecules universally exist in photosynthetic organisms. Chl and carotenoids (Car) are the most abundant pigments that play important functions in plant chloroplast development and photosynthesis [3]. In addition to their well-established function as collectors of light energy for photosynthesis, the Car of higher plant chloroplasts might have an important structural role [3]. Chl molecules universally exist in photosynthetic organisms. They 
perform essential processes of harvesting light energy in the antenna systems and driving electron transfer in the reaction centers [4].

Chloroplast development and $\mathrm{Chl}$ and Car biosyntheses are correlated with organ coloration. Plant Car are red, orange, and yellow lipid-soluble pigments and are embedded in the membranes of chloroplasts. Their colors are masked by $\mathrm{Chl}$ in photosynthetic tissues [5]. Leaf color mutants are the ideal materials for exploring the mechanisms of $\mathrm{Chl}$ and Car biosynthesis and chloroplast development [1,6-10]. Plant leaf color variation is caused by genetic mutations that directly or indirectly affect the synthesis and degradation of $\mathrm{Chl}$, thus changing the Chl content [11,12]. Studies on the molecular mechanisms of leaf color mutants are leading in model crops and field crops. Several genes associated with leaf color mutations have been cloned in Arabidopsis [13,14], rice $[6,7,11,15]$, and tobacco [16], and these genes encode Chl synthesis. In breeding, leaf color variation can be used as marker traits to simplify seed breeding and hybrid production [17]; therefore, discovering and identifying plant Chl-deficient mutant genes have important theoretical significance and application value.

Lipoxygenases (LOXs), widely found in plants, fungi, and animals [18], are a large family of monomeric proteins with non-heme, non-sulfur, and iron cofactor containing dioxygenases that catalyze the oxidation of polyunsaturated fatty acids to yield hydroperoxides [19]. LOXs display diverse functions in mammals and plants. In mammals, they play important roles in the development of acute inflammation [20], and in cancer [21] and vascular biology [22], and they contribute to in vivo metabolism of endobiotics and xenobiotics [23]. Plant LOXs are primarily classified into two major classes, namely, 9- and 13-LOXs, on the basis of their positional specificity to oxygenate linoleic acids [24]. Furthermore, 13-LOXs can be classified into type I and type II on the basis of sequence similarity [25]. Some LOXs can co-oxidize Car [26-31]. Many LOX-related studies have examined the functions of LOXs in plant development and abiotic and biotic stresses [32]. However, the functional differences among the entire LOX gene family in plant species have remained unclear.

Cucumber (Cucumis sativus L.), which belongs to the family Cucurbitaceae, is an economically important vegetable crop worldwide [33]. In the present study, a cucumber mutant that exhibits predominantly yellow-green leaf from spontaneous mutation was discovered. Whole genome resequencing and genetic mapping results showed non-synonymous mutations in the cucumber tandem LOX genes underlying the mutant phenotype. Consistent with the role of LOX in co-oxidation of Car and chloroplast destruction, abnormal chloroplast development was observed in leaf protoplasts of the mutant line. The present study reports the identification of the first mutant of the tandem LOX genes that affect $\mathrm{Chl}$ and Car biosynthesis in higher plants.

\section{Result}

\section{1. ygl1 Mutant Has Reduced Chl Accumulation and Abnormal Chloroplast Development}

ygl1 mutant showing a yellow-green leaf phenotype was a spontaneous mutant isolated from inbred cucumber 1402. ygl1 mutant was slightly smaller than the wild type throughout the developmental stage (Figure 1) and exhibited reduced levels of $\mathrm{Chl} a / b$, as well as Car content (Table 1). Therefore, the net photosynthetic rate of ygll mutant was significantly decreased compared with that of the wild type (Figure 1C). ygll mutant leaves had a $72.7 \%$ and $73.2 \%$ reduction of $\mathrm{Chl}$; however, only $9 \%$ and $10 \%$ reduction of Car levels were detected, compared with those in wild type at the 3- and 12-week-old stage, respectively. Thus, Car in the ygl1 mutant slightly declined to that of the wild-type level. The Car/Pig ratio was $22.87 \%$ and $21.91 \%$ in ygl1 mutant, but only $9.66 \%$ and $7.54 \%$ in wild type at the 3and 12-week-old stage, respectively (Table 1). Thus, ygl1 mutant exhibited severe yellow-green leaf coloration because of high rates of Car accumulation. 

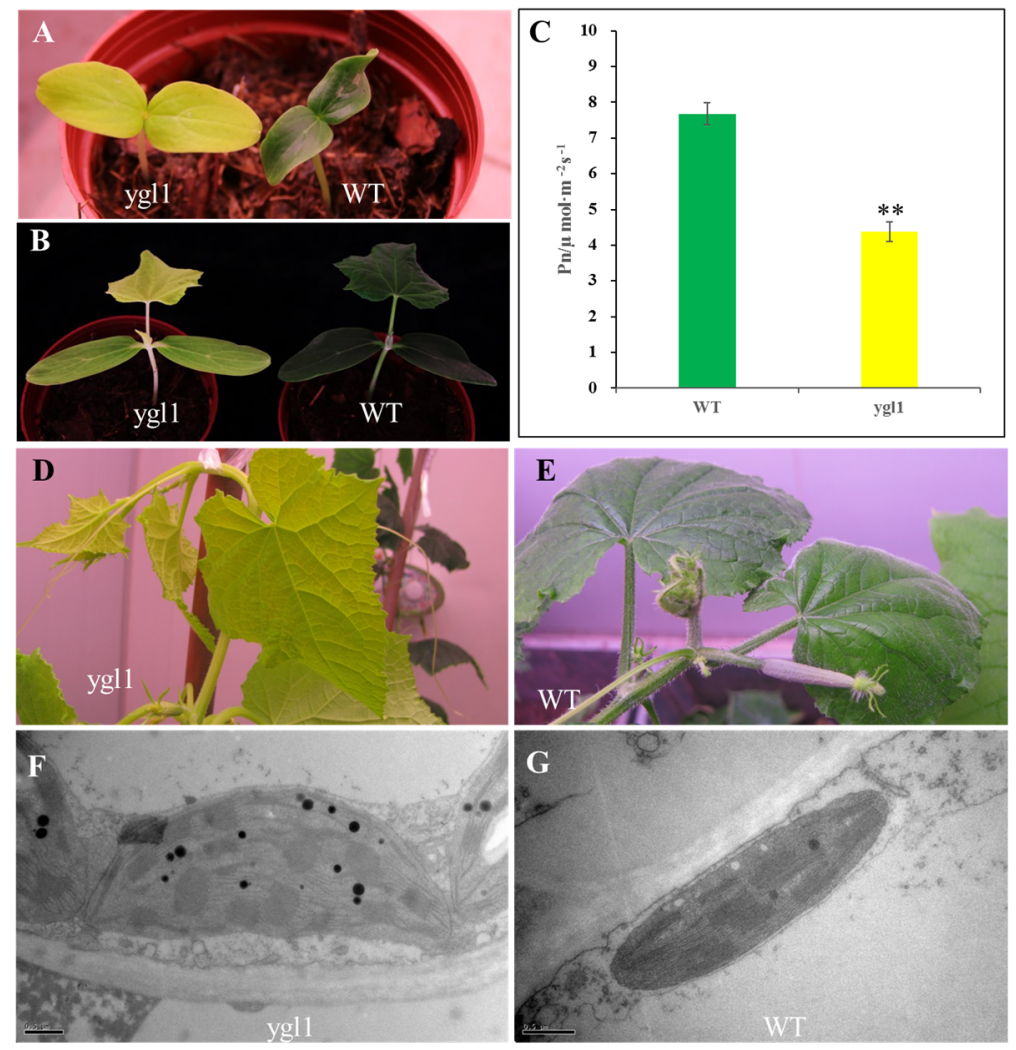

Figure 1. Phenotypic characterization of the cucumber ygl1 mutants. (A) One-week-old plants. (B) Three-week-old plants. (C) Net photosynthesis rate of leaves in ygl1 and wild type (WT) "1402" in cucumber. $n=10,{ }^{* *}$ stands for significant difference $(p<0.01)$. (D,E) Twelve-week-old plants.

(F) Chloroplasts of three-week-old ygl1 mutant have abnormal thylakoid lamellar structure to those of

(G) the wild type with well-ordered thylakoid lamellar structure in three-week-old plants. Bar equals $0.5 \mu \mathrm{m}$.

Table 1. Pigment (Pig) contents in leaves of wild-type and ygl1 mutant, in $\mathrm{mg} / \mathrm{g}$ fresh weight.

\begin{tabular}{cccccc}
\hline Growth Stage & Genotype & Chl a & Chl b & Car & Car/Pig Percent \\
\hline \multirow{2}{*}{ 3 weeks old } & Wild type & $2.39 \pm 0.20$ & $1.31 \pm 0.14$ & $0.39 \pm 0.04$ & $9.66 \pm 2.60$ \\
& ygl1 & $0.76 \pm 0.03$ & $0.25 \pm 0.02$ & $0.30 \pm 0.01$ & $22.87 \pm 1.25$ \\
\multirow{2}{*}{ 2 weeks old } & Wild type & $2.52 \pm 0.15$ & $1.17 \pm 0.07$ & $0.30 \pm 0.02$ & $7.54 \pm 0.75$ \\
& ygl1 & $0.76 \pm 0.06$ & $0.23 \pm 0.05$ & $0.27 \pm 0.01$ & $21.91 \pm 1.39$ \\
\hline
\end{tabular}

$\mathrm{Chl}$ and Car were measured in acetone extracts from third leaf of different growth stages from top. Values shown are the mean SD from three independent determinations.

To investigate how the ygl1 mutation affects chloroplast development, we compared the ultrastructures of plastids in the ygl1 mutant and wild-type plants at three-week-old stages using TEM. The thylakoid lamellar structure in the ygl1 mutant was abnormal, compared with those of wild-type leaves (Figure 1F, G), which might cause a reduction of the net photosynthetic rate (Figure 1C) of ygl1 mutant, thereby explaining the distorted growth of the ygll mutant to that of the wild type (Figure 1).

The phenotype of chloroplasts in the protoplasts isolated from three-week-old leaves of wild-type 1402 and the $y g l 1$ mutant was compared. Each protoplast isolated from the 1402 line contained more than 30 chloroplasts, but less than seven in the ygl1 mutant (Figure 2A-C). 

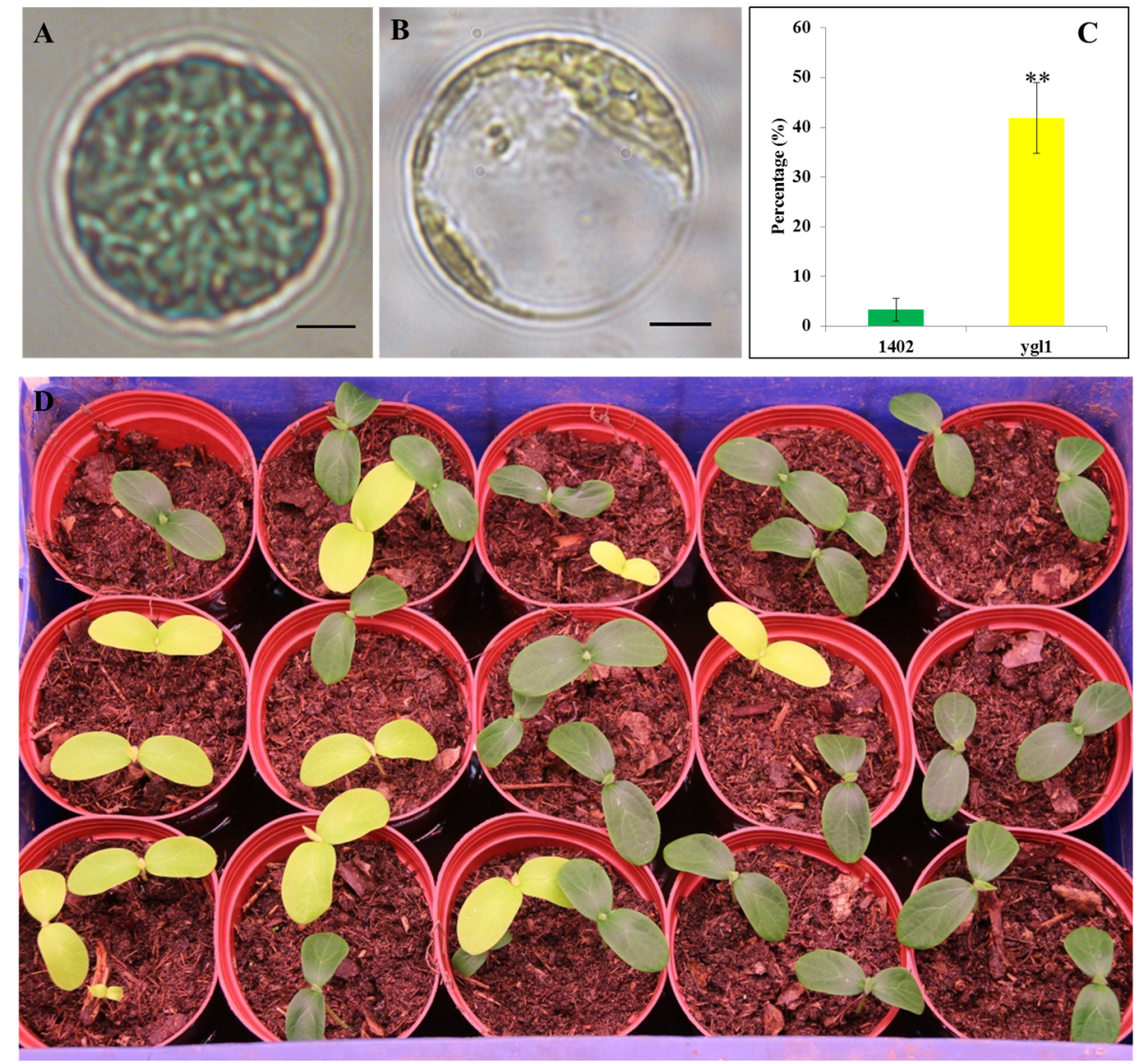

Figure 2. Chloroplast morphology and segregation of $\mathrm{F}_{2}$ populations in wild type 1402 and ygl1 mutant. (A,B) Chloroplast morphology of the protoplast isolated from wild type 1402 and ygl1 mutant leaves. Scale bar $=10 \mu \mathrm{m}$. (C) Quantitative proportion of protoplasts with abnormal chloroplast number in cotyledons infiltrated with agrobacterium. For each biological replicate, 50 protoplasts were counted and an abnormal protoplast harbored less than 15 chloroplasts. ${ }^{* *}$ stands for significant difference $(p<0.01)$. (D) Phenotypic segregation of part $\mathrm{F}_{2}$ populations in wild type 1402 and ygl1 mutant.

\subsection{Identification of the Candidate Gene for ygl1}

For the genetic analysis of the ygl1 mutant, $\mathrm{F}_{2}$ populations were constructed from the crosses between the $y g l 1$ mutant and 1402. All $\mathrm{F}_{1}$ plants from the crosses displayed wild-type phenotype, and among the $156 \mathrm{~F}_{2}$ individuals, 34 displayed light green and 122 normal dark green, which fitted the 1:3 segregation ratio (green/yellow-green plants, $X^{2}<X_{0.05,1}^{2}=3.84 ; p>0.05$; Figure 2D). These results suggested a single recessive gene underlying the mutated yellow-green phenotype.

Whole-genome resequencing was performed on the bulked genomic DNA samples from 33 yellow-green leaf plants and 33 normal plants from the $F_{2}$ population (1402 and ygl1). Illumina high-throughput sequencing generated $28.31 \mathrm{G}$ and $27.95 \mathrm{G}$ clean bases from the 1402 pool and the ygl1 pool, with a coverage of $93.74 \%$ and $93.79 \%$, respectively. The effective sequencing depths for 1402 and $y g l 1$ were 85.73 times and 79.29 times the genome coverage, respectively, which guaranteed the accuracy of subsequent analysis.

Two paternal lines, namely, 1402 and ygl1, were resequenced because no reference genome sequences were available for these two cucumber lines. First, short reads from both parents were aligned with the 9930 genome to obtain two consensus sequences, which were used as reference sequences in the subsequent analysis. Second, reads obtained from two DNA-bulks (i.e., 1402 pool and ygl1 pool) were aligned with consensus sequences to identify single-nucleotide polymorphisms (SNPs). To identify the genomic regions associated with yellow-green leaf, the proportion of SNP 
bases available between the 1402 pool and the ygl1 pool was evaluated. The SNP-index was calculated for each SNP identified in the genome, and the sites with SNP-index less than 0.3 or greater than 0.7 in the 1402 pool and ygl1 pool of this site were removed. The average SNP-index within a $1 \mathrm{Mb}$ window size was computed using a $250 \mathrm{~kb}$ step increment. SNP-index graphs for the 1402 pool and $y g l 1$ pool were plotted by aligning an average SNP-index against the position of each sliding window in the 1402 reference genome (Figure 3A). The $\Delta$ (SNP-index) was calculated and plotted using the information from two graphs for 1402-bulk and ygl1-bulk (Figure 3A). Statistical confidence intervals of $\Delta$ (SNP-index) were calculated for all the SNP positions with given read depths. The chance that $\Delta$ (SNP-index) would become higher than 0.4778 , as observed for the chromosomal region of $11.0-12.0 \mathrm{Mb}$ on chromosome 4 , was $p<0.05$ under the null hypothesis.

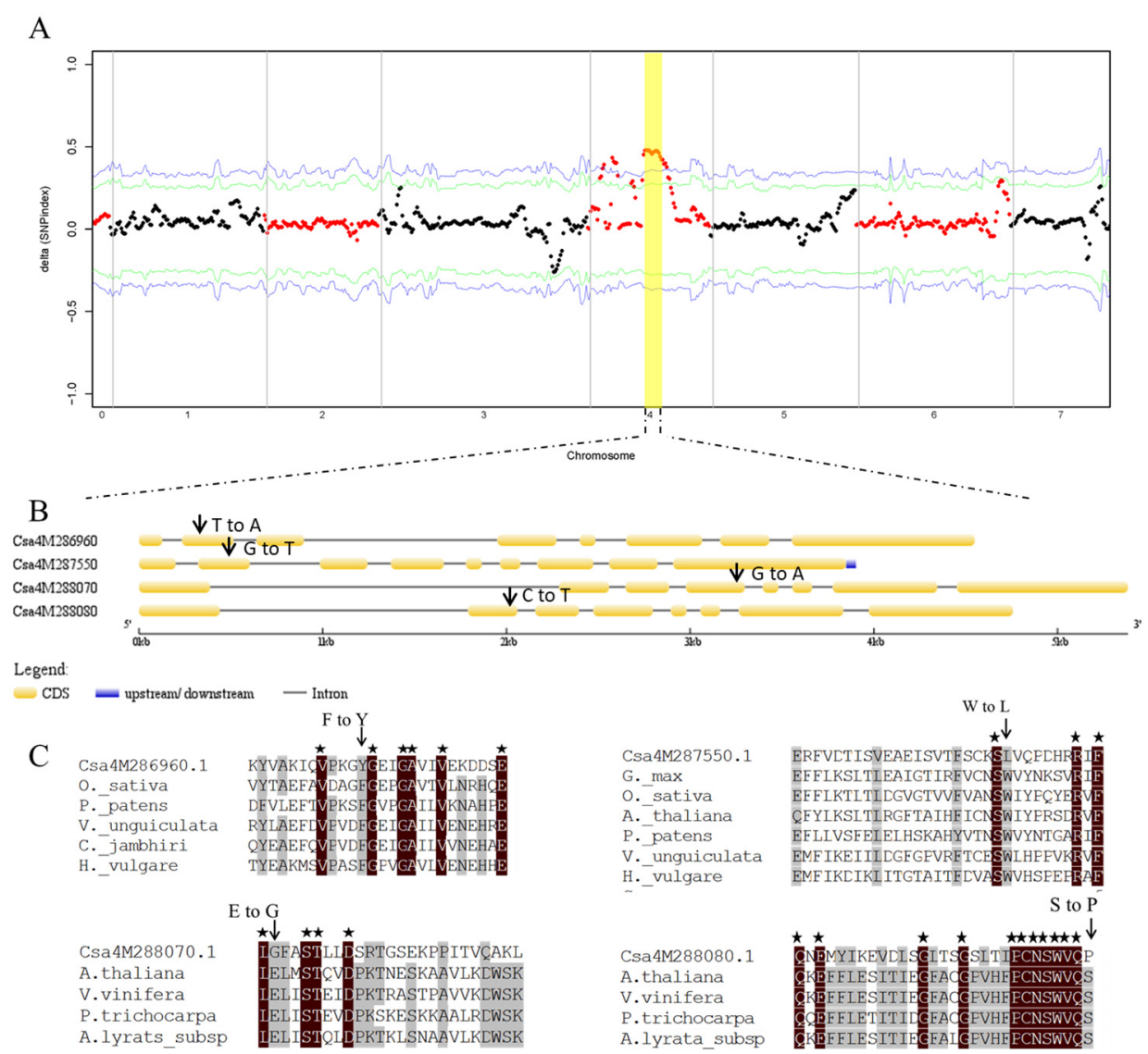

Figure 3. Identification of the gene conferring the yellow-green phenotype. (A) $\Delta$ (SNP-index) distribution of the 1402 and ygl1 pools. The $x$ axis represents the position of seven chromosomes, and the $y$ axis represents the $\Delta$ (SNP-index). The arrow and yellow rectangle indicate the region of chromosome 4 with a $\Delta$ (SNP-index) of approximately 0.5 . The statistical confidence interval under the null hypothesis of no QTLs (Quantitative Trait Locus) was indicated as green $(p<0.05)$ and blue $(p<0.01)$. (B) Gene structure of Csa4M286960, Csa4M287550, Csa4M288070, and Csa4M288080. The black vertical line represents the mutations. (C) Alignment of the LOX genes from diverse species with Csa4M286960, Csa4M287550, Csa4M288070, and Csa4M288080 homologs. Amino acid residues displaying $>50 \%$ identity or similarity between the homologs are shaded black or gray.

A total of 36 putative ORFs (Open Reading Frames 1-36) were predicted in the region (File S1), and 10 LOX genes were present in tandem in the region. LOX isoenzymes have the capacity to co-oxidize Car [26]. Given that ygl1 mutant exhibited severe yellow-green leaf coloration during photomorphogenesis because of high rates of Car accumulation, $10 \mathrm{LOX}$ genes were selected as good candidates for $y g l 1$. Because the target mutation conferred a recessive phenotype, homozygous SNPs in the ygl1 pool in the 10 LOX genes were searched, and 36 SNPs (Table 2) were found. SNPs were 
displayed in all the coding sequences. Thus, non-synonymous SNPs in the $\mathrm{F}_{2}$ populations were examined, and four SNPs co-segregated with the yellow-green phenotype (Figure 3B). Among the four SNPs, SNP4G11124523 displaying a T to A transition between the wild type and ygl1 pool caused a non-synonymous change within the gene Csa4M286960 (F73Y); SNP4G11166969 displaying a G to T transition between the wild type and ygll pool caused a non-synonymous change within the gene Csa4M287550 (W112L); SNP4G 11182070 displaying an A to G transition between the wild type and ygl1 pool caused a non-synonymous change within the gene Csa4M288070 (E384G); and SNP4G11193182 displaying a $\mathrm{C}$ to $\mathrm{T}$ transition between the wild type and ygl1 pool caused a non-synonymous change within the gene Csa4M288080 (S203P) (Figure 3C). To infer the function of gene mutations, a comparison analysis was performed among the LOXs in cucumber and the isolated LOXs in Oryza sativa, Physcomitrella patens, Vigna unguiculate, and so on (Figure 3C). In ygl1 mutant, the mutation led to an amino acid substitution of Csa4M286960 (F73Y), Csa4M287550 (W112L), Csa4M288070 (E384G), and Csa4M288080 (S203P) at a highly conserved residue. It indicated that the mutation sites in the four LOXs were diverse, compared with those of other species (Figure 3C), which implied that SNP mutation resulted in different amino acids, causing phenotypic changes. Moreover, the expression of four LOX genes significantly decreased in the ygl1 mutant compared to the 1402 (Figure S1). Therefore, the combination of genome sequencing, segregation, and expression analysis indicated that four SNPs in four candidate LOX genes probably were the causative mutation of the yellow-green phenotype.

Table 2. Single nucleotide polymorphisms (SNPs) distribution in the region of 10 predicted LOX genes present in tandem in the cucumber genome chromosome 4.

\begin{tabular}{|c|c|c|c|c|c|c|}
\hline Position & Ref & ygl1 & Gene & Translate & aa & Annotation \\
\hline 11124523 & $\mathrm{~A}$ & $\mathrm{~T}$ & Csa4M286960.1 & $\mathrm{TTT}<->\mathrm{TAT}$ & $\mathrm{F}<->\mathrm{Y}$ & Lipoxygenase \\
\hline 11126210 & $\mathrm{~T}$ & G & Csa4M286960.1 & $\mathrm{CCT}<->\mathrm{CCG}$ & $\mathrm{P}<->\mathrm{P}$ & Lipoxygenase \\
\hline 11126739 & A & G & Csa4M286960.1 & TTA $<->$ TTG & $\mathrm{L}<->\mathrm{L}$ & Lipoxygenase \\
\hline 11135803 & $\mathrm{~T}$ & $\mathrm{C}$ & Csa4M286980.1 & GAC $<->$ GAT & $\mathrm{D}<->\mathrm{D}$ & Lipoxygenase \\
\hline 11135804 & A & G & Csa4M286980.1 & GAT<->AAT & $\mathrm{D}<->\mathrm{N}$ & Lipoxygenase \\
\hline 11135807 & $\mathrm{~T}$ & G & Csa4M286980.1 & TGA $<->$ GGA & ${ }^{*}<->G$ & Lipoxygenase \\
\hline 11141217 & A & G & Csa4M286990.1 & $\mathrm{ACG}<->\mathrm{ACA}$ & $\mathrm{T}<->\mathrm{T}$ & Lipoxygenase \\
\hline 11144638 & $\mathrm{C}$ & G & Csa4M287010.1 & GCG $<->$ GGG & $\mathrm{A}<->\mathrm{G}$ & Lipoxygenase \\
\hline 11166969 & $\mathrm{~T}$ & G & Csa4M287550.1 & TGG<-> TTG & $W<->L$ & Lipoxygenase \\
\hline 11167955 & A & $\mathrm{C}$ & Csa4M287550.1 & $\mathrm{GCT}<->\mathrm{GAT}$ & $A<->D$ & Lipoxygenase \\
\hline 11168050 & $\mathrm{C}$ & G & Csa4M287550.1 & $\mathrm{GTT}<->\mathrm{CTT}$ & $\mathrm{V}<->\mathrm{L}$ & Lipoxygenase \\
\hline 11168212 & $\mathrm{~T}$ & $\mathrm{C}$ & Csa4M287550.1 & $\mathrm{TAT}<->\mathrm{TAC}$ & $\mathrm{Y}<->\mathrm{Y}$ & Lipoxygenase \\
\hline 11168253 & $\mathrm{~T}$ & $\mathrm{C}$ & Csa4M287550.1 & $\mathrm{GTT}<->\mathrm{GCT}$ & $\mathrm{V}<->\mathrm{A}$ & Lipoxygenase \\
\hline 11173198 & A & $\mathrm{G}$ & Csa4M287570.1 & $\mathrm{ACA}<->$ ATA & $\mathrm{T}<->\mathrm{I}$ & Unknown protein \\
\hline 11178904 & A & G & Csa4M288070.1 & TGG $<->$ TAG & $\mathrm{W}<->^{*}$ & Lipoxygenase \\
\hline 11179163 & $\mathrm{~T}$ & G & Csa4M288070.1 & TTG $<->$ TTT & $\mathrm{L}<->\mathrm{F}$ & Lipoxygenase \\
\hline 11181197 & $\mathrm{~T}$ & $\mathrm{C}$ & Csa4M288070.1 & TCG $<->$ TTG & $\mathrm{S}<->\mathrm{L}$ & Lipoxygenase \\
\hline 11181330 & A & G & Csa4M288070.1 & $\mathrm{CAA}<->\mathrm{CAG}$ & $\mathrm{Q}<->\mathrm{Q}$ & Lipoxygenase \\
\hline 11181348 & A & G & Csa4M288070.1 & $\mathrm{CAG}<->\mathrm{CAA}$ & $\mathrm{Q}<->\mathrm{Q}$ & Lipoxygenase \\
\hline 11181801 & $\mathrm{~T}$ & G & Csa4M288070.1 & $\mathrm{TCG}<->\mathrm{TCT}$ & $\hat{\mathrm{S}}<->\hat{S}$ & Lipoxygenase \\
\hline 11181936 & $\mathrm{~T}$ & $\mathrm{C}$ & Csa4M288070.1 & GAT $<->$ GAC & $\mathrm{D}<->\mathrm{D}$ & Lipoxygenase \\
\hline 11181988 & A & G & Csa4M288070.1 & GAT<->AAT & $\mathrm{D}<->\mathrm{N}$ & Lipoxygenase \\
\hline 11182010 & $\mathrm{~T}$ & $\mathrm{C}$ & Csa4M288070.1 & $\mathrm{CCT}<->\mathrm{CTT}$ & $\mathrm{P}<->\mathrm{L}$ & Lipoxygenase \\
\hline 11182070 & A & G & Csa4M288070.1 & GAA $<->$ GGA & $E<->G$ & Lipoxygenase \\
\hline 11182092 & A & G & Csa4M288070.1 & $\mathrm{CAG}<->\mathrm{CAA}$ & $\mathrm{Q}<->\mathrm{Q}$ & Lipoxygenase \\
\hline 11182243 & $\mathrm{~T}$ & $\mathrm{C}$ & Csa4M288070.1 & $\mathrm{TTT}<->\mathrm{TTC}$ & $\hat{\mathrm{F}}<->\hat{\mathrm{F}}$ & Lipoxygenase \\
\hline 11190230 & $\mathrm{~T}$ & C & Csa4M288080.1 & $\mathrm{ATC}<->\mathrm{ACC}$ & $\mathrm{I}<->\mathrm{T}$ & Lipoxygenase \\
\hline 11192106 & $\mathrm{~T}$ & $\mathrm{C}$ & Csa4M288080.1 & $\mathrm{ACT}<->\mathrm{ATT}$ & $\mathrm{T}<->\mathrm{I}$ & Lipoxygenase \\
\hline 11192300 & A & G & Csa4M288080.1 & GTA $<->$ GTG & $\mathrm{V}<->\mathrm{V}$ & Lipoxygenase \\
\hline 11192333 & A & G & Csa4M288080.1 & $\mathrm{CAA}<->\mathrm{CAG}$ & $\mathrm{Q}<->\mathrm{Q}$ & Lipoxygenase \\
\hline 11192417 & $\mathrm{~T}$ & C & Csa4M288080.1 & $\mathrm{CTC}<->\mathrm{CTT}$ & $\hat{\mathrm{L}}<->\mathrm{L}$ & Lipoxygenase \\
\hline 11193182 & $\mathrm{~T}$ & C & Csa4M288080.1 & $\mathrm{CCT}<->\mathrm{TCT}$ & $\mathrm{P}<->\mathrm{S}$ & Lipoxygenase \\
\hline 11203061 & A & G & Csa4M288110.1 & GCG $<->$ GCA & $\mathrm{A}<->\mathrm{A}$ & Lipoxygenase \\
\hline 11203109 & $\mathrm{~T}$ & $\mathrm{C}$ & Csa4M288110.1 & $\mathrm{TCC}<->\mathrm{TCT}$ & $S<->S$ & Lipoxygenase \\
\hline 11203161 & A & $\mathrm{T}$ & Csa4M288110.1 & $\mathrm{TAT}<->\mathrm{AAT}$ & $\mathrm{Y}<->\mathrm{N}$ & Lipoxygenase \\
\hline 11216771 & A & $\mathrm{G}$ & Csa4M288610.1 & $\mathrm{ACG}<->\mathrm{ACA}$ & $\mathrm{T}<->\mathrm{T}$ & Lipoxygenase \\
\hline
\end{tabular}

\subsection{Abnormal Chloroplast Morphology in LOX Genes Knockdown Cucumber}

Full-length cDNAs of the four LOX genes were isolated from cucumber via RT-PCR, based on the cucumber genomic sequence. Csa4M286960 (GeneBank Accession number: XP_011653576.1), 
Csa4M287550 (XP_011653578.1), Csa4M288070 (XP_004142236.1), and Csa4M288080 (XP_004142137.1) encoded 831, 821, 904, and 911 amino acids, respectively. The four LOX genes showed high similarity (Figure S2). Among the genes, Csa4M288070 and Csa4M288080 amino acids shared the highest similarity of $76 \%$, and Csa4M288070 and Csa4M287550 shared the lowest similarity of $42 \%$.

Phylogenetic analysis indicated that the four LOX genes were classified in the 13-LOX category into type II (Figure S3), according to the presence or absence of an N-terminal transit peptide of 102 LOX gene sequences from 17 plant species [34].

To further confirm the tandem four LOX gene function, transient RNAi was performed on cotyledons of the wild-type cucumber line 1402. The gene sequences of Csa4M286960, Csa4M287550, Csa4M288070, and Csa4M288080 had high similarity. Thus, separately interfering with the expression of individual genes in this cluster would be difficult. Among the four genes, Csa4M286960 was highly expressed in leaves (Figure S4). Therefore, we selected two target sites, 960-1: 375 bp (referred to as "Ri1" hereafter) and 960-2: $403 \mathrm{bp}$ (referred to as "Ri2" hereafter) fragments of Csa4M286960 for transient RNAi. The expression of LOX genes from the RNAi sample was reduced, compared with that in the control sample in Ri1 and Ri2, except for that of Csa4M287550 in Ri1, which was slightly induced (Figure 4A). Accordingly, the proportion of abnormal protoplasts from the RNAi sample of Ri1 and Ri2 was 2.5 and 6.2 times, respectively, more than that of the control sample (Figure 4B). Compared with that of the control sample, the protoplasts in cotyledons with transient RNAi of 960-1 and 960-2 had fewer chloroplasts (Figure 4C-E) and had similar morphology to that of the chloroplasts in the yellow-green leaves of the ygl1 mutant. The results indicated that the reduced expression of 960-1 might block chloroplast division in cucumber to a certain extent and reduce the expression of 960-2, severely blocking chloroplast division. This finding supported that the LOX genes were the genes underlying the ygl1 mutant.

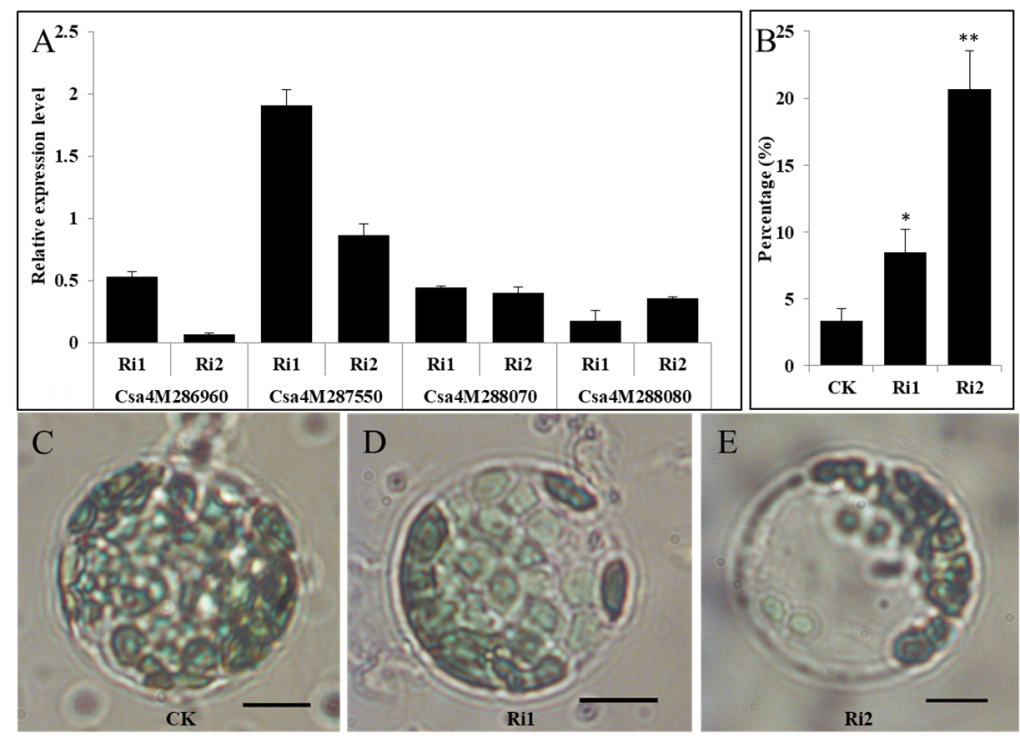

Figure 4. RNAi transient silencing of tandem 13-lipoxygenase genes in cucumber cotyledons. (A) Transient gene expression of tandem 13-lipoxygenase genes in cotyledons infiltrated with agrobacterium. The expressions of each sample infiltrated with RNAi (Ri1 and Ri2) were compared with that of the sample infiltrated with empty vector (CK) after normalization to the cucumber ubiquitin gene and presented as relative expression. (B) Quantitative proportion of protoplasts with abnormal chloroplast number in cotyledons infiltrated with agrobacterium. For each biological replicate, 50 protoplasts were counted, and an abnormal protoplast harbored less than 15 chloroplasts. Error bar indicates standard error. ${ }^{*}$ stands for significant difference $(p<0.05),{ }^{* *}$ stands for significant difference $(p<0.01)$. (C-E) Chloroplast morphology of the representative protoplasts isolated from CK and Ri. Scale bar $=10 \mu \mathrm{m}$. 
VIGS was performed to test whether 960-1 and 960-2 silencing could cause the yellow-green phenotype. VIGS can serve as an alternative to stable transgenic plants to allow the characterization of gene functions in a wide range of plants. Therefore, VIGS silencing of 960-1 and 960-2 was performed on 1402. The results were consistent with the observation on transient RNAi silencing. PDS gene fragments $(300 \mathrm{bp}$ ) amplified from mRNAs of cucumber leaves were inserted into TRV-RNA2 vectors. The resulting viruses (cuPDS-TRV) were inoculated in the cucumber cotyledons. All plants inoculated with $c U P D S-T R V$ developed white leaves with highly uniform PDS knockout phenotype, indicating that the PDS gene had been silenced by cuPDS-TRV (Figure 5A-C).
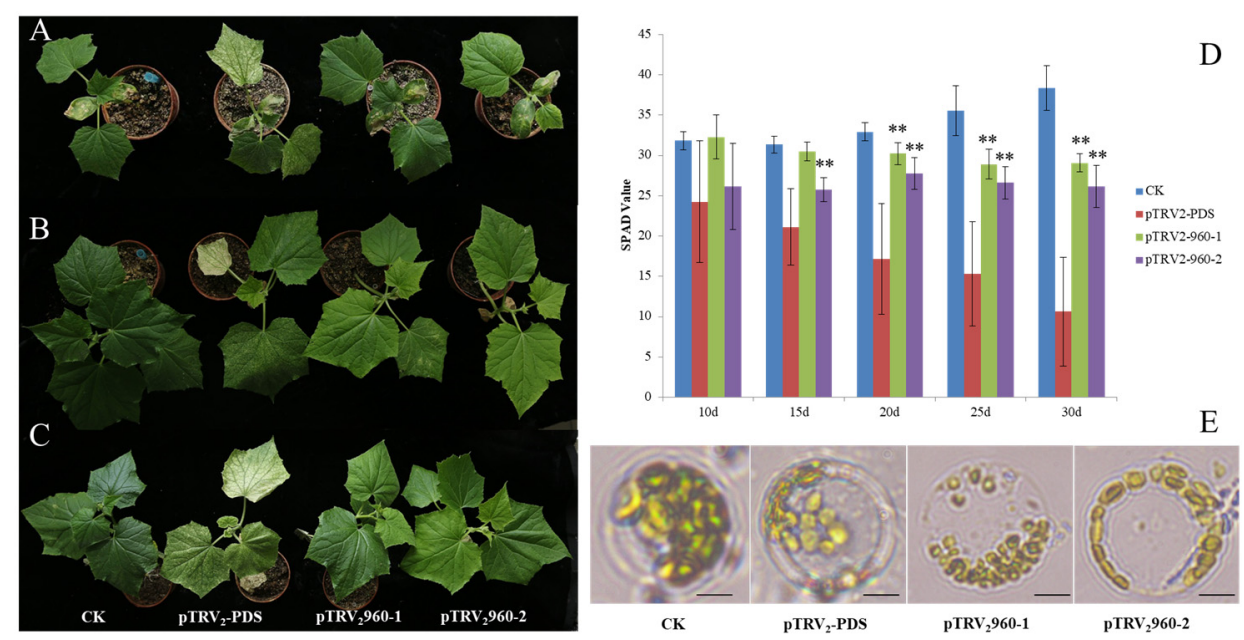

Figure 5. Virus-induced gene silencing in plants infected with TRV vectors of tandem 13-lipoxygenase genes in cucumber leaves. Cucumber leaf morphology co-infected with empty $\mathrm{TRV}_{2}, \mathrm{pTRV}_{2}-P D S$, pTRV $_{2}$-960-1, and pTRV 2 -960-2 after eight days post-inoculation (dpi) (A), 16 dpi (B), and 24 dpi (C). (D) Chl meter (SPAD) value of cucumber leaves co-infected with empty TRV2, pTRV2-PDS, pTRV2-960-1, and pTRV2-960-2 at different dpi. (E) Chloroplast morphology of the representative protoplasts isolated from cucumber leaves, co-infected with empty $\mathrm{TRV}_{2}, \mathrm{pTRV}_{2}-\mathrm{PDS}$, pTRV $2-960-1$, and pTRV $2-960-2$. Scale bar $=10 \mu \mathrm{m} .{ }^{* *}$ stands for significant difference $(p<0.01)$.

Similarly, the plants were infected with 960-1-TRV and 960-2-TRV and the empty vector as a control. As the empty vector of TRV was restricted to the inoculated leaves of cucumber plants, and no silenced phenotypes appeared (Figure 5A-C), the growth of silenced plants was suppressed due to the loss of Chl. The silencing of 960-1-TRV and 960-2-TRV resulted in the yellow-green phenotype, and Chl was significantly reduced, compared with that of the control (Figure 5D). The number of chloroplasts in protoplasts isolated from the control was more than that in cuPDS-TRV, 960-1-TRV, and 960-2-TRV (Figure 5E). Thus, the LOX gene cluster that showed strong association with the yellow-green phenotype was proposed. Although the plants infected with 960-1-TRV and 960-2-TRV showed yellow-green phenotype, the effect was weaker than that of the ygl1 mutant.

\section{Discussion}

LOXs are important dioxygenases in cellular organisms, and they contribute to plant developmental processes and environmental responses [35]. LOXs from several plants have been reported [32]. The Arabidopsis genome comprises six LOXs (i.e., AtLOX1-AtLOX6) [36]. AtLOX1 is induced by pathogen attack, abscisic acid, and methyl jasmonate [37]; AtLOX2 and AtLOX6 are involved in jasmonic acid (JA) biosynthesis [38,39], and AtLOX2 is essential for the formation of green leaf volatiles and five carbon volatiles [40]; AtLOX3 and AtLOX4 are essential for flower development [41]; AtLOX5 plays an important role in lateral root development [42]. In tomato, SILOXA, SILOXB, and SILOXE are upregulated during fruit ripening [43-45]; SILOXC participates in production of flavor compounds resulting from fatty acids [45]; SlLOXD is involved in wound-induced JA biosynthesis, enhancing 
resistance against herbivores and pathogens [46]; SILOXF enhances systemic resistance stimulated by Pseudomonas putida BTP1 [47]. Furthermore, in tobacco, NaLOX2 is involved in green leaf volatiles (GLVs) biosynthesis [48,49]; and in potato, StLOXH1 mediates the biosynthesis of volatile C6-aldehydes (GLVs) involved in defense [50]. The pepper CaLOX1 functions in defense and cell death responses to microbial pathogens [51], and soybean 13-LOX accomplishes a key role in the destruction of chloroplasts in senescing plants and might have a critical role in the NH2-terminal chloroplast transit peptide [52]. However, to our knowledge, no corresponding LOX mutant has been found and no LOX gene was characterized in cucumber. In the present study, the yellow-green leaf LOX mutant of cucumber was identified and functionally characterized. Whole genome resequencing of the wild-type parental line and pooled $\mathrm{F}_{2}$ progenies with mutated phenotype and genetic analysis were conducted, and the causative mutation to an interval with an enrichment of homozygous mutated SNPs was delimited. Mutations of the LOX gene cluster with a $9.2 \mathrm{~kb}$ genomic interval were revealed to underlie the ygl1 mutant.

LOXs, which are widely found in plants, fungi, and animals, are a large family of monomeric proteins with the capacity to co-oxidize Car $[26,28,31]$. Car and Chl are major photosynthetic pigments in plants, and all organisms are capable of photosynthesis. Car of higher plant chloroplasts function as collectors of light energy for photosynthesis and play an important structural role in the membrane stabilization of chloroplasts [3]. The yellow color of fruits and vegetables is attributed to Car and green to Chl [5]. The LOX mutant in the present study contains high levels of car pigments and produces a yellow-green leaf (Figure 1).

The content of photosynthetic pigments in plants is closely related to the variation of plant leaves $[6,53]$. In the present study, the $\mathrm{Chl}$ a and $\mathrm{Chl} b$ content of the mutant leaves was lower than that in the normal plants, indicating that the mutant ygll belongs to the total Chl-type leaf color mutant. The ratio of total Chl to Car in the control was higher than that of the mutant. Therefore, the yellowing of the mutant ygll leaf was caused by a significant decrease in Chl content. The decrease of Chl content could seriously affect photosynthesis. A decrease in plant photosynthetic pigments hinders photochemical conversion efficiency [54]. This finding is consistent with the observation that the net photosynthetic rate of yellow-green leaf mutant ygl1 was $43 \%$ lower than that of the control. The decrease of photosynthetic pigment content in the mutant may affect the net photosynthetic efficiency of the plant.

A 13-LOX enzyme accumulated in the plastid envelope and catalyzed the deoxygenation of unsaturated membrane fatty acids, leading to a selective destruction of the chloroplast and the release of stromal constituents during plant leaf senescence [52]. In our study, the ygll leaf showed reduced Chl accumulation and abnormal chloroplast development upon 13-LOX inhibition. This result is consistent with the observation that the 13-LOX gene LOX2 is essential in the formation of GLVs and five-carbon volatiles [40]. LOX is responsible for the co-oxidation of Car [26]. In the present study, the cucumber LOX mutant displayed yellow-green leaves. Large and few chloroplasts were observed in the leaf protoplasts of the LOX mutant (Figure 2B). Furthermore, the chloroplast phenotype in the ygl1 mutant was very similar to that in LOX transient RNAi and VIGS plants, supporting that the mutation in LOXs underlies chloroplast defects. This evidence suggests that the mutations in LOXs and cucumber ygl1 might affect Car biosynthesis, and chloroplast development may act in similar modes. The relative highly enriched Car phenotype in ygl1 was the result of tandem LOX gene mutation (Table 1). This finding provides overwhelming evidence that LOX isoenzymes have the capacity to co-oxidize Car [26]. Detailed annotation of the $9.2 \mathrm{~kb}$ region harboring the LOX locus identified a cluster of 10 LOX gene analogs. Four LOXs were in the region delimited by SNPs (i.e., SNP4G11124523, SNP4G11166969, SNP4G 11182070, and SNP4G11193182) and were possible candidates of ygl1 mutation.

Carotenoids serve as antenna in the light-harvesting proteins of photosynthesis, which absorb sunlight in the blue and green parts of the solar spectrum and transfer the energy to nearby Chl molecules for photochemical conversion [55]; they also regulate light-energy conversion in photosynthesis and protect plants from reactive oxygen species and coloration [26,56]. In humans, provitamin A Car 
(i.e., $\alpha$-carotene, $\beta$-carotene, $\gamma$-carotene, and the xanthophyll $\beta$-cryptoxanthin) are best known for being converted enzymatically into vitamin $\mathrm{A}$; diseases resulting from vitamin A deficiency remain among the most significant nutritional challenges worldwide [26]. Car are widely consumed, and their consumption is a modifiable health behavior (via diets or supplements), resulting in health benefits for chronic disease prevention. LOX inhibition could block the degradation of most Car in plants, which can be very significant for public health [57]. In the case of golden rice, downregulation of lipoxygenase enzyme activity could reduce degradation of Car, which reduces huge postharvest and economic losses of biofortified rice seeds during storage [27]. In the present work, knockdown LOXs in cucumber retained the high enrichment of Car, and this might shed light on the tools needed to reduce Car losses in plants.

In plants, the occurrence of disease-resistant genes in clusters is critical for generating diversity of resistance specificities because the tandem arrays support high rates of gene conversion and illegitimate recombination [58]. Complex histories of transposon insertions, translocations, and gene duplications and rearrangements have also contributed to the formation of gene clusters [59]. Chromosomal localization and genome distribution of CsLOX genes have revealed that tandem duplication and/or polyploidy duplication based on the cucumber genome annotation database might contribute to the expansion of CsLOX genes. On chromosomes 2 and 4, which are 18 and 20 CsLOX, respectively (Figure S5), a cluster with a relatively high density was observed. These CsLOX members have a high sequence similarity with each other. Exploration of the detailed mechanism of tandem cluster of LOX genes in plant Car metabolism is of significant interest.

\section{Materials and Methods}

\subsection{Plant Materials}

Cucumber (Cucumis sativus L.) ygll (yellow-green leaf) mutant was isolated from a South China-type cucumber inbred line 1402. The ygl1 is a spontaneous natural mutant, after three generations, the inherited stably ygl1 mutant was used for reciprocally crossing with 1402 to construct the $\mathrm{F}_{2}$ segregating population. All plants were grown in a greenhouse in the science and technology building of Southwest University, Chongqing, China.

\subsection{Net Photosynthetic Rate}

The net photosynthetic rates (Pn) of wild type (WT) and ygl1 leaves were measured with CB-1101 photosynthetic system (Siaidi, Beijing, China). The instrument setting parameters are as follows: The light intensity was set to $1000 \mu \mathrm{mol} \cdot \mathrm{m}^{-2} \cdot \mathrm{S}^{-1}$ for measurement. Pn of the plants was determined by setting the chamber temperature to $10^{\circ} \mathrm{C}$, and the constant leaf area was $6.5 \mathrm{~cm}^{2}$. Measurements were carried out in clear and cloudless weather from 9:00 am to 11:00 am. After 30 days of sowing, uniform cucumber leaves were selected from WT and ygl1, and six plants were tested for WT and ygll, respectively, and each assay was repeated 10 times.

\subsection{Transmission Electron Microscopy (TEM) Analysis}

Wild-type and ygl1 mutant leaf samples were harvested from 3-week-old plants grown in a greenhouse. The leaves were cut with a sharp blade into small pieces of approximately $1 \mathrm{~mm}^{2}$. The following procedures were performed as described previously [60] with slight modifications. In brief, leaf sections were fixed in a solution of $2 \%$ glutaraldehyde $(\mathrm{pH}=7.4)$ and further fixed in $2 \% \mathrm{OsO}_{4}$. Tissues were stained with uranyl acetate, dehydrated in ethanol, and embedded in ethoxyline resin prior to thin sectioning. Leica UC6 ultrathin slicer was used for slicing, and uranyl acetate was used for staining. TEM was used to observe and photograph by HITACHI H-7650 (Tokyo, Japan). 


\subsection{Chloroplast Phenotype Analysis}

Isolation of cucumber leaf protoplast and chloroplast phenotype analysis were performed according to the reported method [61]. For each biological replicate, 50 protoplasts were counted, and the protoplast was considered abnormal if it harbored less than 15 chloroplasts.

\subsection{Whole Genome Resequencing}

Genomic DNA was extracted from fresh leaves by using standardized CTAB protocol [62]. The DNA of 33 plants showing a mutant phenotype in the $F_{2}$ population was mixed equally to construct the $y g l 1$ pool. The DNA of 33 plants showing normal green leaves in the $\mathrm{F}_{2}$ population was mixed equally to construct the 1402 pool. Two DNA pools were prepared by mixing equimolar concentration of DNA samples. For Illumina paired-end sequencing, the sequencing library with an insert size of $500 \mathrm{bp}$ was constructed according to the standard protocol. Then, the library with a read length of $100 \mathrm{bp}$ was sequenced using Illumina Hi-Seq 2500 sequencer. The sequencing generated $28.31 \mathrm{G}$ clean base for 1402 and $27.95 \mathrm{G}$ for the $y g l$ pool. In both cases, more than $96 \%$ of bases possessed an Illumina Phred quality score higher than 20.

\subsection{Sequence Data Analysis}

The short reads of the 1402 and ygl1 pools were aligned against the reference genome of cucumber inbred line Cucumis satious L. var. sativus cv. 9930 [63] using BWA-MEM [64]. The output of paired-end alignment files was processed with SAMtools [65] with default parameters to generate consensus genome sequences. The SNP (single nucleotide polymorphism)-index was carried out by directly comparing the consensus sequences of 1402 and ygl1 pools, base-for-base [15]. The index is equal to 1 when all short reads differ from the reference genome, and is equal to 0 when all short reads are identical to the reference genome. In homozygous crops, changes in the SNP-index and $\Delta$ (SNP-index) in the offspring pool are usually caused by the exchange and recombination of homologous chromosomes of the genome of one of the parents taken as the reference sequence.

Using the $\Delta(\mathrm{SNP}$-index) for sliding window analysis, changes in the SNP-index and $\Delta(\mathrm{SNP}$-index) of the SNP sites within the candidate interval are consistent with the recombination section, and the candidate section and the different phenotypes correspond to the sign of the $\Delta$ (SNP-index) window.

Given that the SNP-index was based on a reference genome rather than the genome of the parental line, the origin of each SNP or the linkage around its neighboring region could not be estimated. Positive or negative values of the $\Delta$ (SNP-index) did not correspond to the phenotype of the parental lines. $\Delta$ (SNP-index) was used as the main parameter to identify the target phenotype. The $95 \%$ and $99 \%$ confidence intervals of the $\Delta$ (SNP-index) under the null hypothesis of no QTLs (Quantitative Trait Locus) were calculated following the method described previously [66].

\subsection{Sequence Alignments and Phylogenetic Analysis}

The genome sequences and annotation of cucumber inbred line 9930 are accessible in the GenBank under the accession ACHR00000000. The sequence alignment was performed with ClustalW, and the phylogenetic tree was constructed via neighbor-joining using MEGA5.05.

\subsection{Development of PCR-Based SNP Markers}

SNPs were typed by amplifying an SNP-containing DNA fragment with two flanking primers. All the PCR reactions were performed in a PCR Thermal Cycler SP (Takara). PCR products were visualized using gel electrophoresis on $2 \%(w / v)$ agarose. The primers are summarized in Table S1.

\subsection{Transient Gene Silencing in Cucumber Cotyledons}

Transient RNAi system was performed on cucumber cotyledons according to a previous protocol [67]. To construct the RNA interference vector, 375 bp (Ri1) and 403 bp (Ri2) fragments 
were amplified from the Csa4M286960 coding sequence using primers with a $5^{\prime}$-attB1 extension forward primer and a $5^{\prime}$-attB2 extension reverse primer (Table S1, 5'-attB1 and 5'-attB2 extensions are underlined). A recombination reaction between the PCR product and the pHellsgate 2 vector (Invitrogen, USA) was carried out using BP clonase (Invitrogen) according to the manufacturer's instructions. Constructs were separately transformed into Agrobacterium tumefaciens strain LBA4404. Afterwards, the agrobacterium suspension was infiltrated into cotyledons of wild-type line 1402 seedlings. Five days post-injection infiltrated, the cotyledons were cut off for chloroplast observation and quantitative real-time PCR analysis (the primer sequences are shown in Table S1). Three biological replicates were conducted in this experiment.

\subsection{Chl Content and SPAD Assay}

Chl content was measured via the Lichtenthaler method [68]. Leaf tissues were ground in liquid nitrogen and extracted with $8 \mathrm{~mL}$ of $80 \%(v / v)$ acetone. Absorption spectra were detected at 663 , 646, and $470 \mathrm{~nm}$. Chl was computed using the equation as follows: Chl concentration $(\mathrm{mg} / \mathrm{L})=\mathrm{C}_{\mathrm{a}}=$ $12.21 \mathrm{~A}_{663}-2.81 \mathrm{~A}_{646}, \mathrm{C}_{\mathrm{b}}=20.13 \mathrm{~A}_{646}-5.03 \mathrm{~A}_{663}, \mathrm{C}_{\mathrm{T}}=\mathrm{C}_{\mathrm{a}}+\mathrm{C}_{\mathrm{b}}=17.32 \mathrm{~A}_{646}-7.18 \mathrm{~A}_{663}, \mathrm{C}_{\mathrm{x} . \mathrm{c}}=\left(1000 \mathrm{~A}_{470}-\right.$ $\left.3.27 \mathrm{C}_{\mathrm{a}}-104 \mathrm{C}_{\mathrm{b}}\right) / 229$, where $A$ is the absorbance at a specified wavelength.

$\mathrm{Chl}$ meter values (SPAD values) were taken with the Minolta SPAD-502 Chl meter.

\subsection{Plasmid Construction and Agro-infiltration}

pTRV1 and pTRV2 virus-induced gene silencing (VIGS) vectors were used as described previously [69].

pTRV2-CuPDS construction: The sequence of cucumber PDS genes (EF159942) was amplified from mRNA samples from cucumber leaves using primer pair cuPDS31(+) (corresponding to nt positions 31-50) and cuPDS900(-) (complementary to nt positions 881-900) for a PDS gene (EF159942) [70]. The resulting product was cloned into pTRV2 to form pTRV2-CuPDS.

pTRV2-960-1 construction: The 375 bp fragment of the Csa4M286960 gene was PCR-amplified from cucumber cDNA by using primers $960 \mathrm{TRV}-1 \mathrm{FW}(+)$ (corresponding to nt positions $-3-17$ ) and 960TRV-1RV(-) (complementary to nt positions 353-372). The resulting PCR product was cloned into pTRV2 to form pTRV2-960-1.

pTRV2-960-2 construction: The $403 \mathrm{bp}$ fragment of the 960 gene was PCR amplified from cucumber cDNA by using primers 960TRV-2FW (+) (corresponding to nt positions 427-446) and 960TRV-2RV(-) (complementary to nt positions 810-829). The resulting PCR product was cloned into PTRV2 to form pTRV2-960-2.

The primers are summarized in Table S1, and the added restriction enzymes site of primers is underlined. All the PCR products were cloned into the pMD18-T vector (TaKaRa, Dalian, China) and sequenced, then digested with restriction enzymes Bam HI and Xho I. The resulting product was inserted into the Bam HI and Xho I sites of the vector pTRV2 to yield the above construction.

Plant infiltration was performed as described previously [71]. Agrobacterium strain GV3101 containing pTRV1 or pTRV2 and its derivatives was used for VIGS experiments. Agrobacterium strain GV3101 containing TRV-VIGS vectors was grown at $28^{\circ} \mathrm{C}$ in LB medium containing $10 \mathrm{~mm}$ MES and $20 \mathrm{~mm}$ acetosyringe with appropriate antibiotics. After $24 \mathrm{~h}$, Agrobacterium cells were harvested and resuspended in the Agrobacterium infiltration buffer $(10 \mathrm{~mm} \mathrm{MgCl}, 10 \mathrm{~mm}$ MES, pH 5.6, $150 \mathrm{~mm}$ acetosyringone) to a final $\mathrm{OD}_{600}$ of 1.0 (for both pTRV1 and pTRV2 or its derivatives) and shaken for 4-6 h at room temperature before infiltration. For cucumber leaf infiltration, each Agrobacterium strain containing PTRV1 and PTRV2 or its derivative vectors was mixed in a 1:1 ratio and infiltrated into the cucumber leaves with a $1 \mathrm{~mL}$ needleless syringe.

\subsection{Statistical Analysis}

Data was analyzed using variance by SAS software (version 8.0, SAS Institute, NC, USA), and statistical differences were compared using Fisher's least significant difference (LSD) test. 
Supplementary Materials: The following are available online at http://www.mdpi.com/1422-0067/20/12/3102/s1, Figure S1. Real-time PCR expression analysis of four candidate LOX genes between ygl1 and 1402. Numbers 1,2 , and 3 indicates three individual biological repeats. Figure S2. Multiple alignments in deduced amino acid of four candidate LOX genes. Figure S3. Phylogenetic analysis of four candidate LOX genes. An unrooted neighbor-joining phylogenetic tree was constructed from 102 LOX proteins from 17 plant species. A bootstrap test was set to 1000 replicates to validate tree classification confidence. The bootstrap values of the confidence levels are shown as percentages at branch nodes. The four candidate LOX genes are highlighted in circles. Figure S4. Heat map of four candidate LOX genes in various tissues. The RNA-seq expression data of different tissues were used to construct tissue expression patterns of $L O X$ genes. The four candidate $L O X$ genes are highlighted in red boxes. Figure S5. Chromosome distribution and duplication events of LOX genes in cucumber. Chromosomal mapping was based on the physical position $(\mathrm{Mb})$ in seven cucumber chromosomes. Chromosome number is indicated at the top of each bar. Positions of the cucumber LOX genes in the chromosomes were obtained from Cucurbit Genomics Database (CuGenDB: http://cucurbitgenomics.org/). Black blocks indicate the centromere positions in chromosomes. Scale represents $10 \mathrm{Mb}$ chromosomal distance. Table S1. Primer sequences used for qPCR and gene cloning. File S1. Candidate genes and annotation in the region of chromosome 4 with an $\triangle$ SNP-index of approximately 0.5 .

Author Contributions: Writing—original draft and supervision, J.L.; investigation and data curation, Y.D., W.Y., C.S., and H.M.; methodology, Y.P. and X.Z.; project administration, J.L.

Funding: This work was sponsored by grants National Natural Science Foundation of China (No. 31872123 and 31872119), Natural Science Foundation of Chongqing, China (cstc2019jcyj-msxm2289).

Conflicts of Interest: The authors declare no conflict of interest.

\section{References}

1. Ming, M.; Ying, W.; Qibing, L.; Yihua, W.; Zhijun, C. Identification and gene mapping of a yellow-leaf rice mutant ys94. Crops 2016, 4, 41-46.

2. Long, S.P.; Zhu, X.G.; Naidu, S.L.; Ort, D.R. Can improvement in photosynthesis increase crop yields? PlantCell Environ. 2006, 29, 315-330. [CrossRef]

3. Havaux, M. Carotenoids as membrane stabilizers in chloroplasts. Trends Plant Sci. 1998, 3, 147-151. [CrossRef]

4. Fromme, P.; Melkozernov, A.; Jordan, P.; Krauss, N. Structure and function of photosystem i: Interaction with its soluble electron carriers and external antenna systems. FEBS Lett 2003, 555, 40-44. [CrossRef]

5. Bartley, G.E.; Scolnik, P.A. Plant carotenoids: Pigments for photoprotection, visual attraction, and human health. Plant Cell 1995, 7, 1027. [CrossRef] [PubMed]

6. Dong, H.; Fei, G.-L.; Wu, C.-Y.; Wu, F.-Q.; Sun, Y.-Y.; Chen, M.-J.; Ren, Y.-L.; Zhou, K.-N.; Cheng, Z.-J.; Wang, J.-L. A rice virescent-yellow leaf mutant reveals new insights into the role and assembly of plastid caseinolytic protease in higher plants. Plant Physiol. 2013, 162, 1867-1880. [CrossRef] [PubMed]

7. Huang, R.; Wang, Y.; Wang, P.; Li, C.; Xiao, F.; Chen, N.; Li, N.; Li, C.; Sun, C.; Li, L. A single nucleotide mutation of ispf gene involved in the mep pathway for isoprenoid biosynthesis causes yellow-green leaf phenotype in rice. Plant Mol. Biol. 2018, 96, 5-16. [CrossRef] [PubMed]

8. Liu, X.-p.; Yang, C.; Han, F.-q.; Fang, Z.-y.; Yang, L.-m.; Zhuang, M.; Lv, H.-h.; Liu, Y.-m.; Li, Z.-s.; Zhang, Y.-y. Genetics and fine mapping of a yellow-green leaf gene (ygl-1) in cabbage (brassica oleracea var. Capitata 1.). Mol. Breed. 2016, 36, 1-8. [CrossRef]

9. Nothnagel, T.; Straka, P. Inheritance and mapping of a yellow leaf mutant of carrot (daucus carota). Plant Breed. 2003, 122, 339-342. [CrossRef]

10. Zhang, K.; Liu, Z.; Shan, X.; Li, C.; Tang, X.; Chi, M.; Feng, H. Physiological properties and chlorophyll biosynthesis in a pak-choi (brassica rapa 1 . Ssp. Chinensis) yellow leaf mutant, pylm. Acta Physiol. Plant. 2017, 39, 22. [CrossRef]

11. Wu, Z.; Zhang, X.; He, B.; Diao, L.; Sheng, S.; Wang, J.; Guo, X.; Su, N.; Wang, L.; Jiang, L.; et al. A chlorophyll-deficient rice mutant with impaired chlorophyllide esterification in chlorophyll biosynthesis. Plant Physiol 2007, 145, 29-40. [CrossRef] [PubMed]

12. Gao, M.; Hu, L.; Li, Y.; Weng, Y. The chlorophyll-deficient golden leaf mutation in cucumber is due to a single nucleotide substitution in cschli for magnesium chelatase i subunit. Theor. Appl. Genet. 2016, 129, 1961-1973. [CrossRef] [PubMed]

13. Beale, S.I. Green genes gleaned. Trends Plant Sci 2005, 10, 309-312. [CrossRef] [PubMed] 
14. Nagata, N.; Tanaka, R.; Satoh, S.; Tanaka, A. Identification of a vinyl reductase gene for chlorophyll synthesis in arabidopsis thaliana and implications for the evolution of prochlorococcus species. Plant Cell 2005, 17, 233-240. [CrossRef] [PubMed]

15. Abe, A.; Kosugi, S.; Yoshida, K.; Natsume, S.; Takagi, H.; Kanzaki, H.; Matsumura, H.; Yoshida, K.; Mitsuoka, C.; Tamiru, M.; et al. Genome sequencing reveals agronomically important loci in rice using mutmap. Nat. Biotechnol. 2012, 30, 174-178. [CrossRef] [PubMed]

16. Monde, R.A.; Zito, F.; Olive, J.; Wollman, F.A.; Stern, D.B. Post-transcriptional defects in tobacco chloroplast mutants lacking the cytochrome b6/f complex. Plant J. 2000, 21, 61-72. [CrossRef]

17. Zhao, Y.; Wang, M.L.; Zhang, Y.Z.; Du, L.F.; Pan, T. A chlorophyll-reduced seedling mutant in oilseed rape, brassica napus, for utilization in $\mathrm{f}-1$ hybrid production. Plant Breed. 2000, 119, 131-135. [CrossRef]

18. Grechkin, A. Recent developments in biochemistry of the plant lipoxygenase pathway. Prog. Lipid Res. 1998, 37, 317-352. [CrossRef]

19. Kuhn, H.; Saam, J.; Eibach, S.; Holzhütter, H.-G.; Ivanov, I.; Walther, M. Structural biology of mammalian lipoxygenases: Enzymatic consequences of targeted alterations of the protein structure. Biochem. Biophys. Res. Commun. 2005, 338, 93-101. [CrossRef]

20. Ivanov, I.; Heydeck, D.; Hofheinz, K.; Roffeis, J.; O’Donnell, V.B.; Kuhn, H.; Walther, M. Molecular enzymology of lipoxygenases. Arch. Biochem. Biophys. 2010, 503, 161-174. [CrossRef]

21. Bhattacharya, S.; Mathew, G.; Jayne, D.G.; Pelengaris, S.; Khan, M. 15-lipoxygenase-1 in colorectal cancer: A review. Tumour Biol. 2009, 30, 185-199. [CrossRef] [PubMed]

22. Chawengsub, Y.; Gauthier, K.M.; Campbell, W.B. Role of arachidonic acid lipoxygenase metabolites in the regulation of vascular tone. Am. J. Physiol. Heart Circ. Physiol. 2009, 297, H495-H507. [CrossRef] [PubMed]

23. Kulkarni, A.P. Lipoxygenase-a versatile biocatalyst for biotransformation of endobiotics and xenobiotics. Cell Mol Life Sci 2001, 58, 1805-1825. [CrossRef] [PubMed]

24. Feussner, I.; Wasternack, C. The lipoxygenase pathway. Annu. Rev. Plant Biol. 2002, 53, 275-297. [CrossRef] [PubMed]

25. Liavonchanka, A.; Feussner, I. Lipoxygenases: Occurrence, functions and catalysis. J. Plant Physiol. 2006, 163, 348-357. [CrossRef] [PubMed]

26. Chedea, V.S.; Jisaka, M. Lipoxygenase and carotenoids: A co-oxidation story. Afr. J. Biotechnol. $2013,12$.

27. Gayen, D.; Ali, N.; Sarkar, S.N.; Datta, S.K.; Datta, K. Down-regulation of lipoxygenase gene reduces degradation of carotenoids of golden rice during storage. Planta 2015, 242, 353-363. [CrossRef] [PubMed]

28. Wu, Z.; Robinson, D.S.; Hughes, R.K.; Casey, R.; Hardy, D.; West, S.I. Co-oxidation of $\beta$-carotene catalyzed by soybean and recombinant pea lipoxygenases. J. Agric. Food Chem. 1999, 47, 4899-4906. [CrossRef]

29. Cabibel, M.; Nicolas, J. Lipoxygenase from tomato fruit (lycopersicon esculentum 1.). Partial purification, some properties and in vitro cooxidation of some carotenoid pigments. Sci. Des Aliment. 1991, 11, 177-290.

30. Biacs, P.; Daood, H. Lipoxygenase-catalysed degradation of carotenoids from tomato in the presence of antioxidant vitamins. Biochem. Soc. Trans. 2000, 28, 839-845. [CrossRef]

31. Aziz, S.; Wu, Z.; Robinson, D.S. Potato lipoxygenase catalysed co-oxidation of $\beta$-carotene. Food Chem. 1999, 64, 227-230. [CrossRef]

32. Sarde, S.J.; Kumar, A.; Remme, R.N.; Dicke, M. Genome-wide identification, classification and expression of lipoxygenase gene family in pepper. Plant Mol. Biol. 2018, 98, 375-387. [CrossRef] [PubMed]

33. Zhang, W.W.; Pan, J.S.; He, H.L.; Zhang, C.; Li, Z.; Zhao, J.L.; Yuan, X.J.; Zhu, L.H.; Huang, S.W.; Cai, R. Construction of a high density integrated genetic map for cucumber (Cucumis sativus L.). Appl. Genet. 2012, 124, 249-259. [CrossRef] [PubMed]

34. Zhu, J.; Wang, X.; Guo, L.; Xu, Q.; Zhao, S.; Li, F.; Yan, X.; Liu, S.; Wei, C. Characterization and alternative splicing profiles of lipoxygenase gene family in tea plant (camellia sinensis). Plant Cell Physiol. 2018, 59, 1765-1781. [CrossRef] [PubMed]

35. Chen, Z.; Chen, X.; Yan, H.; Li, W.; Li, Y.; Cai, R.; Xiang, Y. The lipoxygenase gene family in poplar: Identification, classification, and expression in response to meja treatment. PLoS ONE 2015, 10, e0125526. [CrossRef] [PubMed]

36. Umate, P. Genome-wide analysis of lipoxygenase gene family in arabidopsis and rice. Plant Signal. Behav. 2011, 6, 335-338. [CrossRef] [PubMed] 
37. Melan, M.A.; Dong, X.; Endara, M.E.; Davis, K.R.; Ausubel, F.M.; Peterman, T.K. An arabidopsis thaliana lipoxygenase gene can be induced by pathogens, abscisic acid, and methyl jasmonate. Plant Physiol. 1993, 101, 441-450. [CrossRef] [PubMed]

38. Bell, E.; Creelman, R.A.; Mullet, J.E. A chloroplast lipoxygenase is required for wound-induced jasmonic acid accumulation in arabidopsis. Proc. Natl. Acad. Sci. USA 1995, 92, 8675-8679. [CrossRef]

39. Grebner, W.; Stingl, N.; Oenel, A.; Mueller, M.J.; Berger, S. Lipoxygenase 6-dependent oxylipin synthesis in roots is required for abiotic and biotic stress resistance of arabidopsis thaliana. Plant Physiol. 2013, 161, 2159-2170. [CrossRef]

40. Mochizuki, S.; Sugimoto, K.; Koeduka, T.; Matsui, K. Arabidopsis lipoxygenase 2 is essential for formation of green leaf volatiles and five-carbon volatiles. FEBS Lett. 2016, 590, 1017-1027. [CrossRef]

41. Caldelari, D.; Wang, G.; Farmer, E.E.; Dong, X. Arabidopsis lox3 lox4 double mutants are male sterile and defective in global proliferative arrest. Plant Mol. Biol. 2011, 75, 25-33. [CrossRef] [PubMed]

42. Vellosillo, T.; Martínez, M.; López, M.A.; Vicente, J.; Cascón, T.; Dolan, L.; Hamberg, M.; Castresana, C. Oxylipins produced by the 9-lipoxygenase pathway in arabidopsis regulate lateral root development and defense responses through a specific signaling cascade. Plant Cell 2007, 19, 831-846. [CrossRef] [PubMed]

43. Griffiths, A.; Barry, C.; Alpuche-Solis, A.G.; Grierson, D. Ethylene and developmental signals regulate expression of lipoxygenase genes during tomato fruit ripening. J. Exp. Bot. 1999, 50, 793-798. [CrossRef]

44. Ferrie, B.J.; Beaudoin, N.; Burkhart, W.; Bowsher, C.G.; Rothstein, S.J. The cloning of two tomato lipoxygenase genes and their differential expression during fruit ripening. Plant Physiol. 1994, 106, 109-118. [CrossRef] [PubMed]

45. Chen, G.; Hackett, R.; Walker, D.; Taylor, A.; Lin, Z.; Grierson, D. Identification of a specific isoform of tomato lipoxygenase (tomloxc) involved in the generation of fatty acid-derived flavor compounds. Plant Physiol. 2004, 136, 2641-2651. [CrossRef]

46. Yan, L.; Zhai, Q.; Wei, J.; Li, S.; Wang, B.; Huang, T.; Du, M.; Sun, J.; Kang, L.; Li, C.-B. Role of tomato lipoxygenase $\mathrm{d}$ in wound-induced jasmonate biosynthesis and plant immunity to insect herbivores. PLoS Genet. 2013, 9, e1003964. [CrossRef]

47. Mariutto, M.; Duby, F.; Adam, A.; Bureau, C.; Fauconnier, M.-L.; Ongena, M.; Thonart, P.; Dommes, J. The elicitation of a systemic resistance by pseudomonas putida btp1 in tomato involves the stimulation of two lipoxygenase isoforms. BMC Plant Biol. 2011, 11, 29. [CrossRef]

48. Allmann, S.; Halitschke, R.; Schuurink, R.C.; Baldwin, I.T. Oxylipin channelling in nicotiana attenuata: Lipoxygenase 2 supplies substrates for green leaf volatile production. PlantCell Environ. 2010, 33, 2028-2040. [CrossRef]

49. VanDoorn, A.; Kallenbach, M.; Borquez, A.A.; Baldwin, I.T.; Bonaventure, G. Rapid modification of the insect elicitor n-linolenoyl-glutamate via a lipoxygenase-mediated mechanism on nicotiana attenuata leaves. BMC Plant Biol. 2010, 10, 164. [CrossRef]

50. León, J.; Royo, J.; Vancanneyt, G.; Sanz, C.; Silkowski, H.; Griffiths, G.; Sánchez-Serrano, J.J. Lipoxygenase h1 gene silencing reveals a specific role in supplying fatty acid hydroperoxides for aliphatic aldehyde production. J. Biol. Chem. 2002, 277, 416-423. [CrossRef]

51. Hwang, I.S.; Hwang, B.K. The pepper 9-lipoxygenase gene calox1 functions in defense and cell death responses to microbial pathogens. Plant Physiol. 2010, 152, 948-967. [CrossRef] [PubMed]

52. Springer, A.; Kang, C.; Rustgi, S.; Von Wettstein, D.; Reinbothe, C.; Pollmann, S.; Reinbothe, S. Programmed chloroplast destruction during leaf senescence involves 13-lipoxygenase (13-lox). Proc. Natl. Acad. Sci. USA 2016, 113, 3383-3388. [CrossRef] [PubMed]

53. Yang, D.L.; Li, S.; Li, M.F.; Yang, X.L.; Wang, W.T.; Cao, Z.Y.; Li, W. Physiological characteristics and leaf ultrastructure of a novel chlorophyll-deficient chd6 mutant of vitis venifera cultured in vitro. J. Plant Growth Regul. 2012, 31, 124-135. [CrossRef]

54. Rohacek, K.; Bartak, M. Technique of the modulated chlorophyll fluorescence: Basic concepts, useful parameters, and some applications. Photosynthetica 1999, 37, 339-363. [CrossRef]

55. Kodis, G.; Herrero, C.; Palacios, R.; Marino-Ochoa, E.; Gould, S.; De La Garza, L.; Van Grondelle, R.; Gust, D.; Moore, T.A.; Moore, A.L. Light harvesting and photoprotective functions of carotenoids in compact artificial photosynthetic antenna designs. J. Phys. Chem. B 2004, 108, 414-425. [CrossRef]

56. Nisar, N.; Li, L.; Lu, S.; Khin, N.C.; Pogson, B.J. Carotenoid metabolism in plants. Mol. Plant 2015, 8, 68-82. [CrossRef] 
57. Mayne, S. Carotenoids a Colorful and Timely Research Field; CRC Press, Taylor and Francisc Group: Boca Raton, FL, USA, 2010.

58. Hulbert, S.H.; Webb, C.A.; Smith, S.M.; Sun, Q. Resistance gene complexes: Evolution and utilization. Annu Rev. Phytopathol. 2001, 39, 285-312. [CrossRef]

59. Smith, L.M.; Bomblies, K.; Weigel, D. Complex evolutionary events at a tandem cluster of arabidopsis thaliana genes resulting in a single-locus genetic incompatibility. PLoS Genet. 2011, 7, e1002164. [CrossRef]

60. Zhao, H.; Yu, L.; Huai, Z.X.; Wang, X.H.; Ding, G.D.; Chen, S.S.; Li, P.; Xu, F.S. Mapping and candidate gene identification defining bnchd1-1, a locus involved in chlorophyll biosynthesis in brassica napus. Acta Physiol. Plant. 2014, 36, 859-870. [CrossRef]

61. Zhou, Q.; Wang, S.; Hu, B.; Chen, H.; Zhang, Z.; Huang, S. An accumulation and replication of chloroplasts 5 gene mutation confers light green peel in cucumber. J. Integr. Plant Biol. 2015, 57, 936-942. [CrossRef]

62. Dellaporta, S.L.; Wood, J.; Hicks, J.B. A plant DNA minipreparation: Version ii. Plant Mol. Biol. Report. 1983, 1, 19-21. [CrossRef]

63. Huang, S.; Li, R.; Zhang, Z.; Li, L.; Gu, X.; Fan, W.; Lucas, W.J.; Wang, X.; Xie, B.; Ni, P.; et al. The genome of the cucumber, Cucumis sativus L. Nat. Genet. 2009, 41, 1275-1281. [CrossRef] [PubMed]

64. Li, H.; Durbin, R. Fast and accurate short read alignment with burrows-wheeler transform. bioinformatics 2009, 25, 1754-1760. [CrossRef] [PubMed]

65. Li, H.; Handsaker, B.; Wysoker, A.; Fennell, T.; Ruan, J.; Homer, N.; Marth, G.; Abecasis, G.; Durbin, R. The sequence alignment/map format and samtools. Bioinformatics 2009, 25, 2078-2079. [CrossRef] [PubMed]

66. Takagi, H.; Abe, A.; Yoshida, K.; Kosugi, S.; Natsume, S.; Mitsuoka, C.; Uemura, A.; Utsushi, H.; Tamiru, M.; Takuno, S. Qtl-seq: Rapid mapping of quantitative trait loci in rice by whole genome resequencing of DNA from two bulked populations. Plant J. 2013, 74, 174-183. [CrossRef] [PubMed]

67. Shang, Y.; Ma, Y.; Zhou, Y.; Zhang, H.; Duan, L.; Chen, H.; Zeng, J.; Zhou, Q.; Wang, S.; Gu, W.; et al. Plant science. Biosynthesis, regulation, and domestication of bitterness in cucumber. Science 2014, 346, 1084-1088. [CrossRef] [PubMed]

68. Lichtenthaler, H.K. Chlorophylls and carotenoids: Pigments of photosynthetic biomembranes. Methods Enzymol. 1987, 148C, 350-382.

69. Fu, D.Q.; Zhu, B.Z.; Zhu, H.L.; Jiang, W.B.; Luo, Y.B. Virus-induced gene silencing in tomato fruit. Plant J. 2005, 43, 299-308. [CrossRef]

70. Igarashi, A.; Yamagata, K.; Sugai, T.; Takahashi, Y.; Sugawara, E.; Tamura, A.; Yaegashi, H.; Yamagishi, N.; Takahashi, T.; Isogai, M.; et al. Apple latent spherical virus vectors for reliable and effective virus-induced gene silencing among a broad range of plants including tobacco, tomato, arabidopsis thaliana, cucurbits, and legumes. Virology 2009, 386, 407-416. [CrossRef]

71. Ratcliff, F.; Martin-Hernandez, A.M.; Baulcombe, D.C. Technical advance. Tobacco rattle virus as a vector for analysis of gene function by silencing. Plant J. 2001, 25, 237-245. [CrossRef] 